\title{
Breaking bony bridges by physeal distraction
}

\author{
J. Cañadell and J. de Pablos
}

Department of Orthopaedic Surgery, University Clinic of Navarra, Pamplona, Spain

Address offprint requests to: Professor Dr. J. Cañadell, Department of Orthopaedic Surgery, University Clinic of Navarra, 31008 Pamplona, Spain

\section{SUMMARY}

Physeal distraction for breaking bony bridges and the late treatment of long bone deformities in children near maturity, has been used in our Department since June, 1983. In all cases ( 4 bones in 3 patients) a deformity was present at the extremity of a long bone due to a bony bridge caused by a previous injury to the growth cartilage. The results were excellent and in our opinion there are advantages over other methods. The operation itself is not extensive and very little damage is done. There is no need for internal fixation or bone grafts. It is possible to obtain lengthening and to adjust the angular correction during treatment.

We conclude that it is possible to correct angular deformities and bone shortening due to bony bridges by physeal distraction without the need for resection of the bony bridge. At present we recommend this method in children near skeletal maturity, especially in those cases with bone shortening.

\section{RÉSUMÉ}

Nous avons eu recours depuis Juin 1983 à la distraction épiphysaire pour rompre les ponts osseux et pour le traitement ultérieur des déformations des os longs chez les enfants en fin de croissance. Dans tous les cas (4 os chez 3 malades) il existait une déformation de l'extrémité d'un os long due à un pont osseux résultant d'un traumatisme antérieur du cartilage de conjugaison. Les résultats ont été excellents et à notre avis cette méthode présente de nombreux avantages par rapport aux autres. L'opération ellemême est peu agressive et n'entraîne que très peu de dommages. Elle ne nécessite ni matériel de synthèse ni greffe osseuse. Elle permet d'obtenir un allongement et de rectifier la correction d'une angulation au cours du traitement.

Pour concluye nous estimons qu'il est possible de corriger les déformations axiales et les raccourcissements dus à un pont osseux par la distraction épiphysaire, sans qu'il soit besoin de réséquer le pont osseux. Nous recommandons cette méthode chez les enfants en fin de croissance, notamment dans les cas qui comportent un raccourcissement osseux.

KEY WORDS: Physeal bone bridge, Physeal distraction 


\section{INTRODUCTION}

Numerous aetiological factors create lesions of growth cartilage which in turn give rise to the formation of physeal bony bridges. The presence of these bony bridges in the long bones ultimately brings about angular deformities, shortening or, more commonly, deformity and shortening together.

Up to 1967, the recommended treatment for bony bridges included corrective osteotomies, which might have to be repeated several times during the growth period, and arrest of growth of the functional portion of the injured physis by means of stapling [2] or by epiphysiodesis [16].

In 1967, as an alternative to this type of palliative treatment, a direct approach by resection of the bony bridge and the interpolation of autologous fat was suggested [10] in an attempt to reestablish the integrity of the physeal plate with regard to both its structure and function. This principle was also used in conditions, normally traumatic in origin, where it was anticipated that a bony bridge would develop in time. The technique was carried out in experimental animals and in children $[1,13,14]$. Finally, the treatment of bony bridges was established as a combination of bridge resection, interposition of materials and corrective osteotomy, all at one operation [3].

Physeal distraction was originally described as a procedure for lengthening bone using the growth cartilage as a "locus minor resistentiae" at which lengthening could be obtained $[6,8,9,18,20,21]$.

At our centre, in addition to the aim of lengthening, we have used this treatment for correcting angular deformities affecting the ends of growing long bones in which bony bridges were not present. From this application of physeal distraction and on the basis of other experimental studies $[4,5,15,17]$, angular deformities and shortening caused by physeal bony bridges were treated by this method, without previous resection of the bridges.

\section{CLINICAL CASES}

\section{Case 1}

J. C. M., a 12-year-old boy, was brought to our department with a varus deformity of his left ankle. One year previously he had sustained a fracture of the distal part of the shaft of the left tibia and fibula which had been treated conservatively in a plaster cast. The cast produced a pressure sore with subsequent osteomyelitis which eventually healed after antibiotic treatment. A free skin graft had been carried out. Radiographs showed consolidation of the fracture in a varus position. There was widening of the ankle mortise and a distal tibio-fibular synostosis, with an extensive bony bridge across the distal tibial physis (Figs. 1a and 2a). Shortening of $1.5 \mathrm{~cm}$ was present.

Physeal distraction was undertaken using a hinged external fixator which permitted progressive distraction $(1 \mathrm{~mm} /$ day) of the distal tibial epiphysis in relation to the tibial diaphysis and the fibula on the same side (Fig. $1 \mathrm{~b}$ ). Once the widening of the ankle mortise was corrected, a fibular osteotomy was performed and Tater the tibio-fibular mortise was realigned (Fig. $1 \mathrm{c}$ ). 
Immediately after correction of the angular deformity, which also overcame the minimal shortening, the fixator was locked and finally removed a month and a half Tater. Treatment lasted for 3 months. The final radiographs after 8 months showed that the correction obtained initially was maintained (Figs. 1d and 2b). On the basis of subsequent radiographs it will be decided whether or not a distal epiphysiodesis of the fibula will be performed, depending on its rate of growth compared to that of the adjacent tibia.

\section{Case 2}

B. B. I., a 13-year-old girl, came to our department with deformities of both knees which followed a meningococcal infection when 6 months old. The patient's parents had first observed the deformities at the age of 7 . At the age of 9 the patient underwent a right tibial osteotomy, after which the deformity recurred.

Radiographs showed a valgus deformity of the femur and a varus deformity of the tibia in both legs. There were bony bridges on the lateral side of the distal femoral physis and the medial side of the distal tibial physis on both sides (Figs. 3 a, 5 a and 6 a). Bilateral genu recurvatum was also present. Treatment of the left knee was undertaken by the same method used in case 1, with distal femoral physeal distraction (Fig. 3) followed by proximal tibial physeal distraction after the orientation of the distal femoral epiphysis had been corrected (Figs. 4b and 5b).

Five months passed from the time of placement of the external femoral fixator and removal of the tibial device, each having been in place for 3 months (Fig. $5 \mathrm{c}$ ).

The final radiographs taken one year after the end of treatment showed that correction had been satisfactorily maintained (Figs. $6 \mathrm{~b}$ and $7 \mathrm{~b}$ ).

\section{Case 3}

G. S. L., a 13-year-old boy, presented with a varus deformity of his right knee which followed a serious soft tissue injury on the inner side and back of the knee at the age of 5 . His parents first noticed the deformity when he was 8 years of age.

At the age of 11 years the patient had undergone a distal femoral osteotomy, but the deformity recurred. Radiographs showed a varus deformity of the distal femoral physis with a medial bony bridge (Fig. 8). This was partially compensated for by a valgus angulation of the proximal tibial physis. The affected lower extremity was $5.5 \mathrm{~cm}$ short.

Distraction of the distal femoral physis was first performed in order to obtain lengthening (Figs. 9 a-c) and then to achieve the desired angular correction (Fig. 9d). Temporary stapling was also performed on the inner aspect of the upper tibial physis to correct the compensatory valgus. The treatment covered a period of $5^{1 / 2}$ months.

The final radiographs taken 9 months after treatment showed that correction had been satisfactorily maintained (Fig. 9 e). 


\section{DISCUSSION}

Physeal distraction has a number of advantages as a method for correcting deformities caused by the presence of physeal bony bridges. The procedure acts directly on the bony bridge which is the cause of the deformity unlike corrective osteotomies or other methods for retarding physeal growth such as stapling [2] or epiphysiodesis [16], which accept that the condition of the bridge is irreversible. These traditional procedures should be considered as palliative only. The method causes only minimal surgical damage at the site of correction which might partly explain the ease with which consolidation occurs. None of our cases required bone-grafting.

Distraction proves to be immediately effective as shown by the radiological evidence which in all cases demonstrates the breaking of the physeal bridge a few days after distraction began, and subsequently allowed for a satisfactory correction of the deformities and shortening. We consider this method to have a clear advantage over stapling [2], epiphysiodesis [16] or resection-interposition [10, 11, 12, 19]. Correction is not consistently obtained by these procedures and at best is achieved only after a considerable time.

The extent of the angular correction and lengthening, and the rate at which these can be best obtained, can be easily controlled. Rapid correction, and the consequent risk of damage to vessels and nerves, can be avoided. External control permits adjustment of the angular correction as necessary and allows simultaneous bone lengthening. There is no need for further operations to remove implants. The external fixator can be removed without anaesthesia.

However, three unresolved questions lead us to proceed with caution in the use of this method.

First, there is uncertainty as to the possibility of recurrence of the physeal bony bridge and the angular deformity following treatment. This is unlikely when treatment is undertaken near to skeletal maturity; at an earlier age, if longitudinal growth of the remaining physeal plate is not resumed, and if there is not functional reintegration of the physis to the point of normality, the deformity and shortening will probably recur. Experimental study is needed before the clinical application of the method to younger children is justified.

In order to avoid this problem, certain authors [7] after experimental study have combined Langenskiöld's technique with physeal distraction at the same time. We are not convinced that such a combination is necessary, but if it were we believe it would be best carried out in two stages because of the importance of completely filling the defect created by resection of the bony bridge with the material to be inserted [1, 14]. If physeal distraction is applied immediately afterwards, there is a risk of displacing the inserted material, which might result in the reformation of a bony bridge.

The second question involves the viability of the remaining growth cartilage in the affected physis. In an experimental study carried out in our centre on intact physes in the distal femur of lambs, we observed satisfactory viability of growth cartilage when a symmetrical distraction speed of $0.5 \mathrm{~mm} /$ day was applied [6]. 
It would be appropriate here to emphasize a technical detall. The correction of the angular deformity as the first step calls for utilization of the healthy portion of the physis as a fulcrum on which corrective rotational movement takes place. This submits the healthy part of the physis to pressures which could lead to it's permanent damage. For this reason we recommend first performing symmetrical physeal distraction with no angular correction and, afterwards, when the whole of the physis has been satisfactorily detached, correcting the angular deformity.

The third question about which we continue to have doubts concerns the maximum area of a bony bridge which could be subjected to physeal distraction. We cannot yet offer any definite answer, although in our third case the bridge occupied approximately $40 \%$ of the total growth cartilage in the antero-posterior view (Fig. 8). The ease with which the breaking of the bridge occurred, indicated by an absence of pain or other complications, would suggest that the method should succeed even when a greater area was involved.

We therefore consider our method to be indicated specifically for patients near skeletal maturity, particularly where there is also shortening.

Our present approach in the treatment of bony bridges is as follows:

In young children we recommend Langenskiöld's method as a first step in attempting to restore the morphological and functional integrity of damaged growth cartilage. Some authors have described spontaneous correction of angular deformities by this technique without the need to resort to other methods $[10,11,12,19]$.

When an isolated angular deformity is not corrected spontaneously following Langenskiöld's treatment, we use complementary physeal distraction. When shortening accompanies angular deformity we use physeal distraction to correct both. In those rare instances of shortening alone we use metaphyseal corticotomy as a second stage procedure.

In children near skeletal maturity when angular deformity is present with or without shortening; we use physeal distraction in a one-stage procedure to correct both the deformity and shortening. In those rare instances of shortening alone we use metaphyseal corticotomy.

In our experience physeal distraction allows for correction of angular deformities and shortening due to the presence of physeal bony bridges and avoids the need to resect them.

\section{REFERENCES}

1. Baeza V (1978) Prophylaxis of the partial block of the growth cartilage. An experimental study. Doctoral Thesis, University of Navarra, Pamplona

2. Blount WP, Clark GR (1949) Control of bone growth by epiphyseal stapling. Preliminary report. J Bone Joint Surg 31-A: 464-478

3. Cass JR, Peterson HA (1983) Salter-Harris type IV injuries of the distal tibial epiphyseal growth plate, with emphasis on those involving the medial malleolus. $J$ Bone Joint Surg 65-A: 1059-1070 
4. Connolly JF, Huurman W, Ray S (1979) Physeal distraction treatment of fracture deformities. Orthop Trans 3: 231-232

5. Connolly JF, Huurman W, Pankaj R (1982) Long term effect of physeal distraction. Orthop Trans 6: 267

6. de Pablos J (1984) Bone lengthening by physeal distraction. An experimental study. Doctoral Thesis, University of Navarra, Pamplona

7. Foster BK, Rozenbilds M, Yates R (1984) A pilot study of the growth potential of the physis in a sheep tibia model. J Bone Joint Surg 66-B: 778

8. Ilizarov GA, Sohybelman LM (1969) Some clinical and experimental data on the bloodless lengthening of lower limbs. Exp Khir Anest 4: 27-32

9. Ilizarov GA, Soybelman LM, Chirkova AM (1970) Some roentgenologic and morphological data on regeneration of bone tissue in experimental distraction epiphysiolysis. Ortop Tramatol Protez 31: 26-45

10. Langenskiöld A (1967) The possibilities of eliminating premature partial closure of an epiphyseal plate caused by trauma or disease. Acta Orthop Scand 38: 267-279

11. Langenskiöld A (1975) An operation for partial closure of an epiphyseal plate in children and its experimental basis. J Bone Joint Surg 57-B: 325-330

12. Langenskiöld A (1981) Surgical treatment of partial closure of the growth plate. J Pediatr Orthop 1: 3-11

13. Ogden JA (1982) Skeletal injury in the child, Philadelphia, Lea and Febiger, pp 99101

14. Osterman K (1972) Operative elimination of partial premature epiphyseal closure. Acta Orthop Scand [Suppl]: 147

15. Peltonen J, Karaharku E, Alitalo J (1984) Experimental epiphyseal distraction producing and correcting angular deformities. J Bone Joint Surg 66-B: 598-602

16. Phemister DB (1933) Operative arrestment of longitudinal growth of bones in the treatment of deformities. J Bone Joint Surg 5: 1-15

17. Ray SK, Connolly JF, Huurman W (1980) Distraction treatment of deformities due to physeal fractures. Surgical Forum Vol. XXXI, 543

18. Ring PA (1958) Experimental bone lengthening by epiphyseal distraction. Br J Surg 49: 169-173

19. Versveld GA (1984) Surgical management of partial closure of the growth plate. J Bone Joint Surg 66-B: 460

20. Zavijalov PV, Plaskin JT (1967) Elongation of crural bones in children using a method of distraction epiphysiolysis. Vestn Khir Grekova 103: 67-82

21. Zavijalov, PV, Plaskin JT (1968) Distraction epiphysiolysis in lengthening of the lower extremity in children. Khirurgija 44: 121-137 


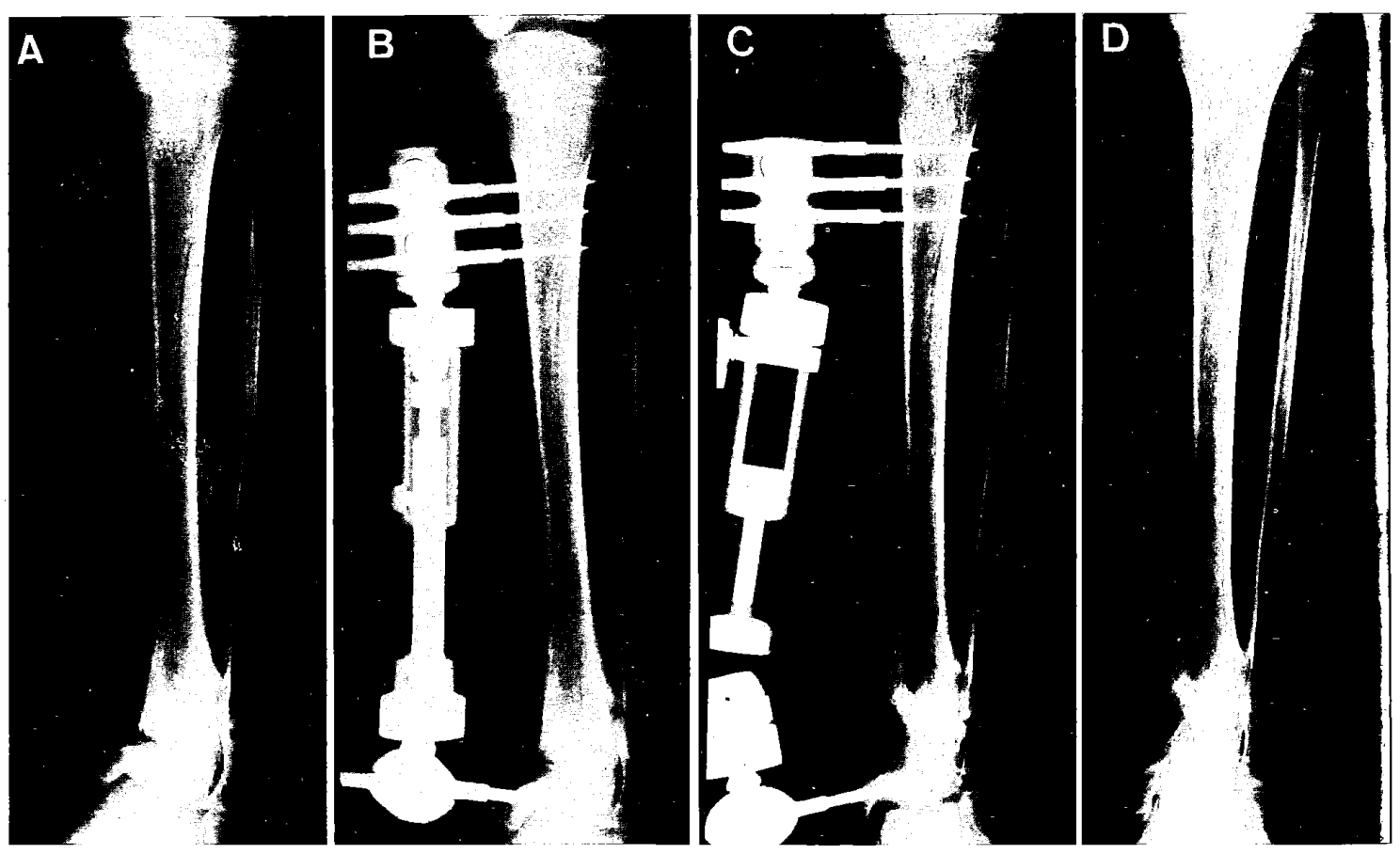

Figure 1 A-D. Case 1. A Before operation; B 20 days after operation; C 2 months after operation and $\mathbf{D} 8$ months after operation

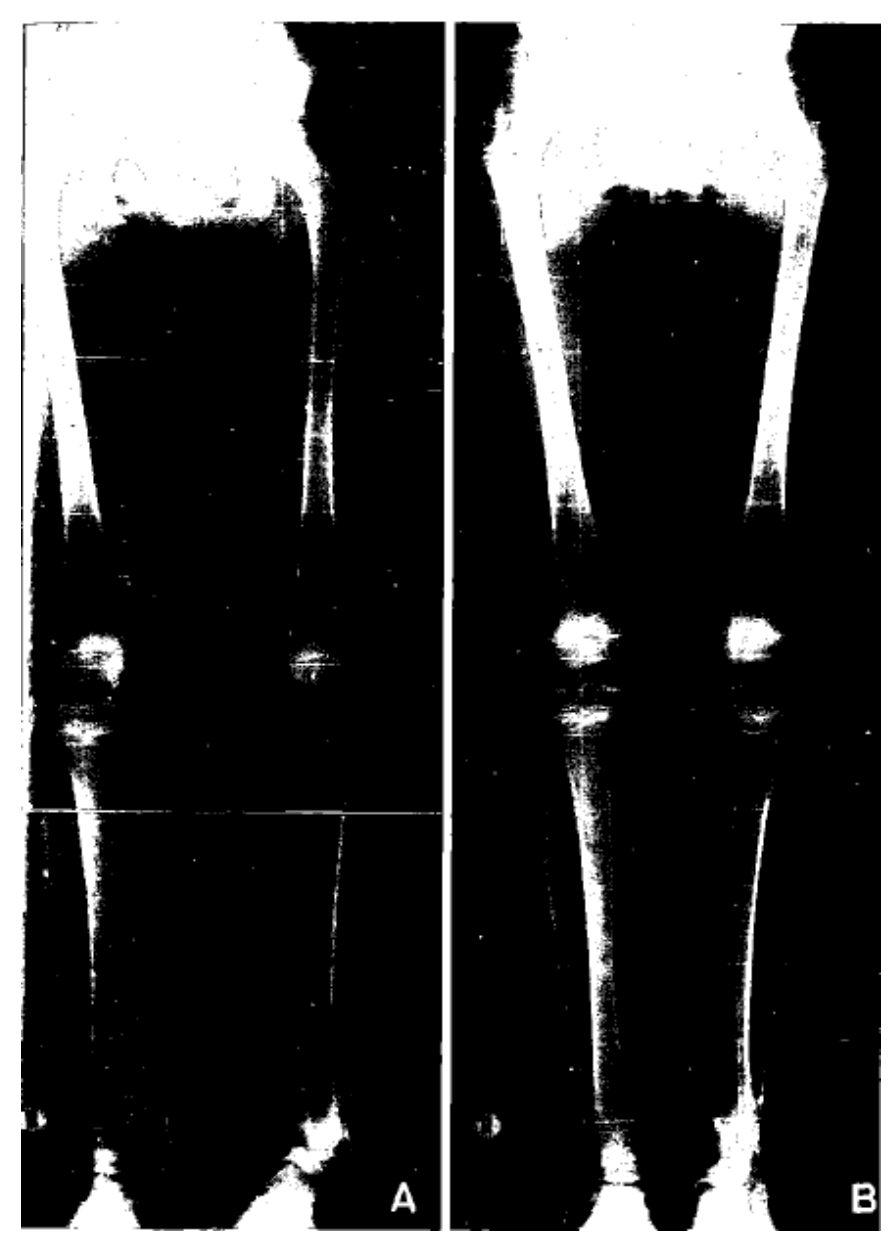

Figure 2 A, B. Case 1. A Before operation and B 8 months after operation 


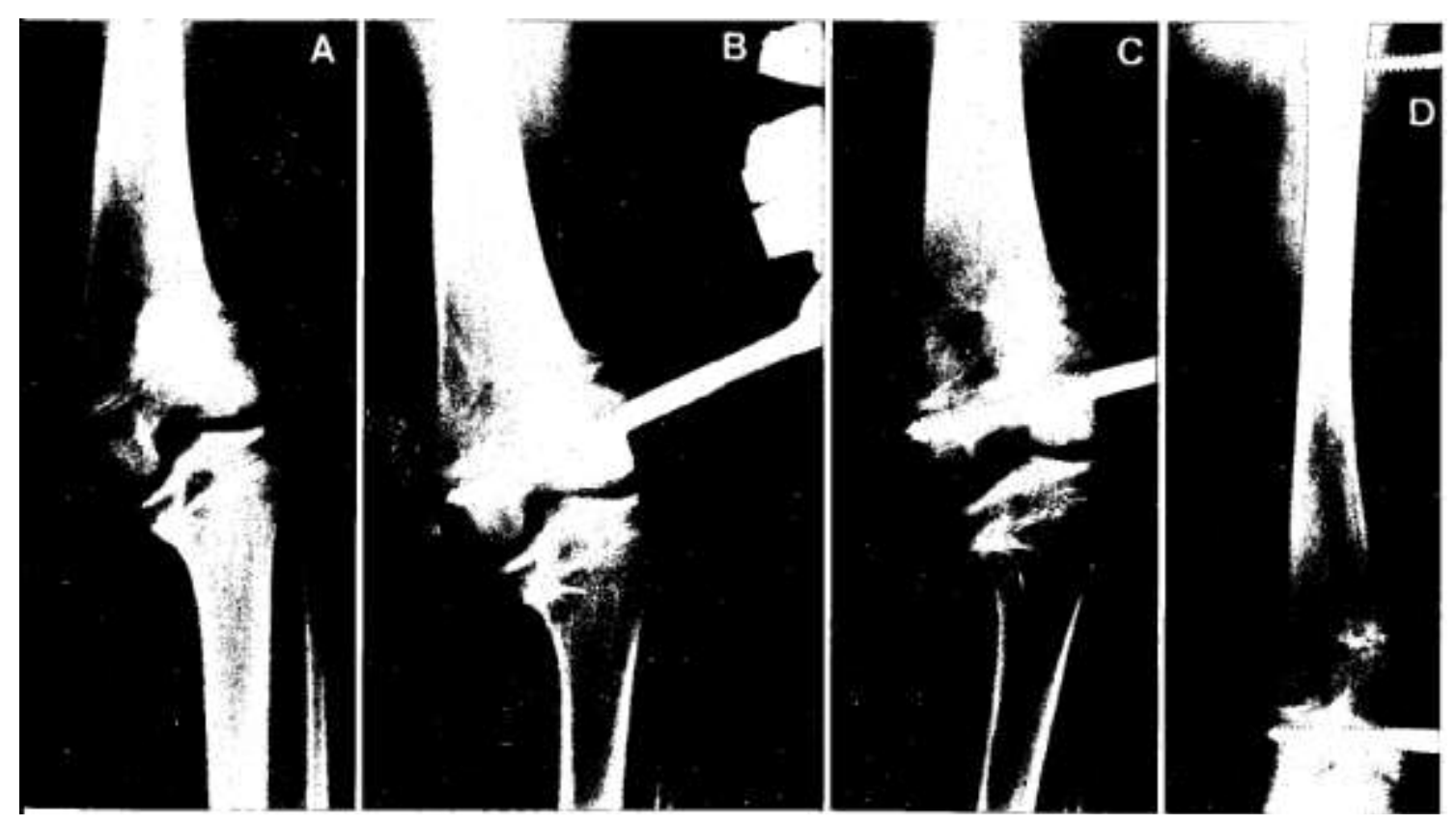

Figure 3 A-D. Case 2. Femoral correction. A Before operation; B 15 days after operation; $C$ one month after operation; $\mathbf{D}$ shows correction achieved at 45 days after operation
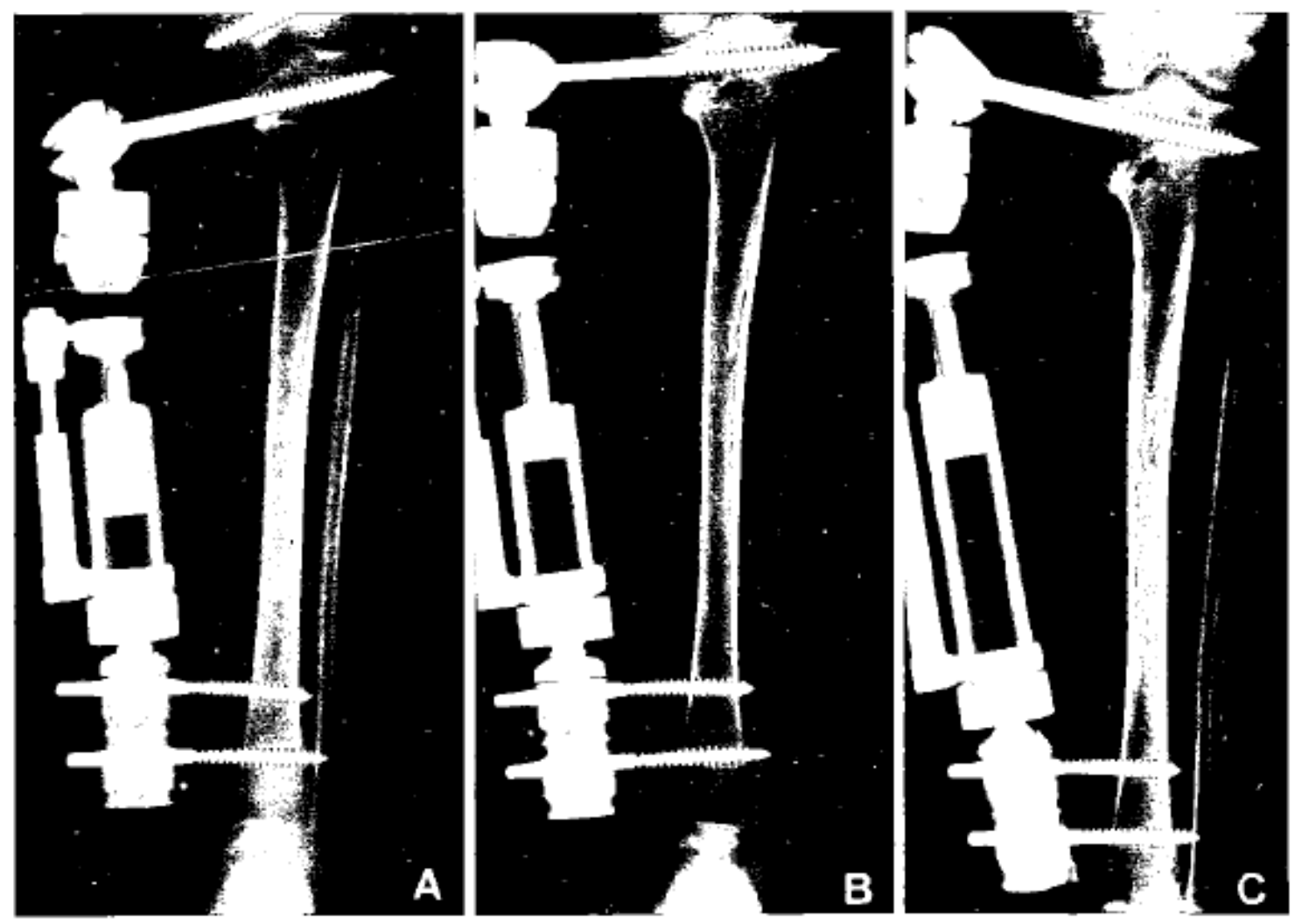

Figure 4 A-C. Case 2. Tibial correction. A Immediately after operation; B 20 days after operation and $\mathbf{C}$ correction at 40 days after operation 


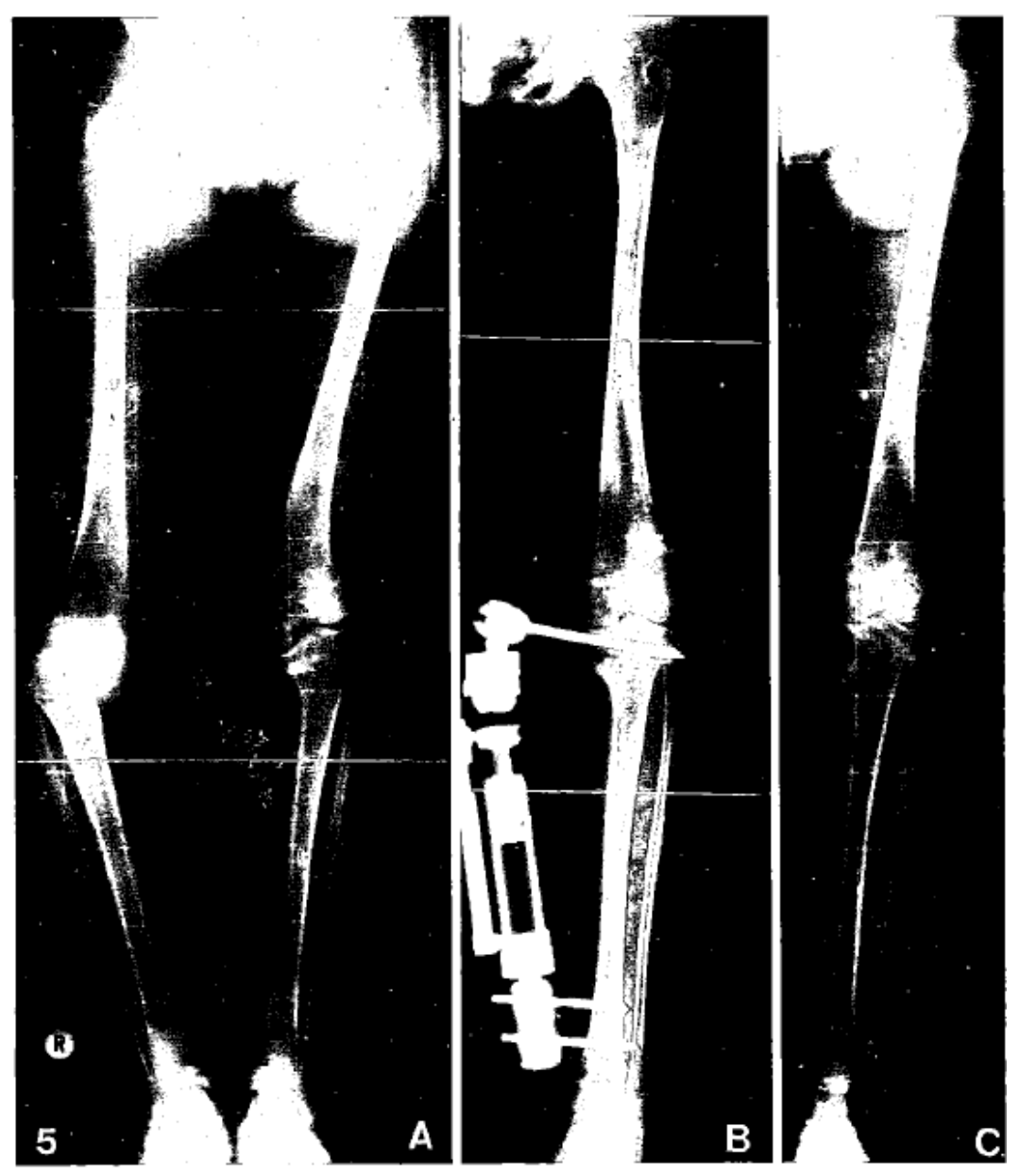

Figure 5 A-C. Case 2. A Before operation; $\mathbf{B}$ just after tibial correctional and $\mathbf{C} 5$ months after operation

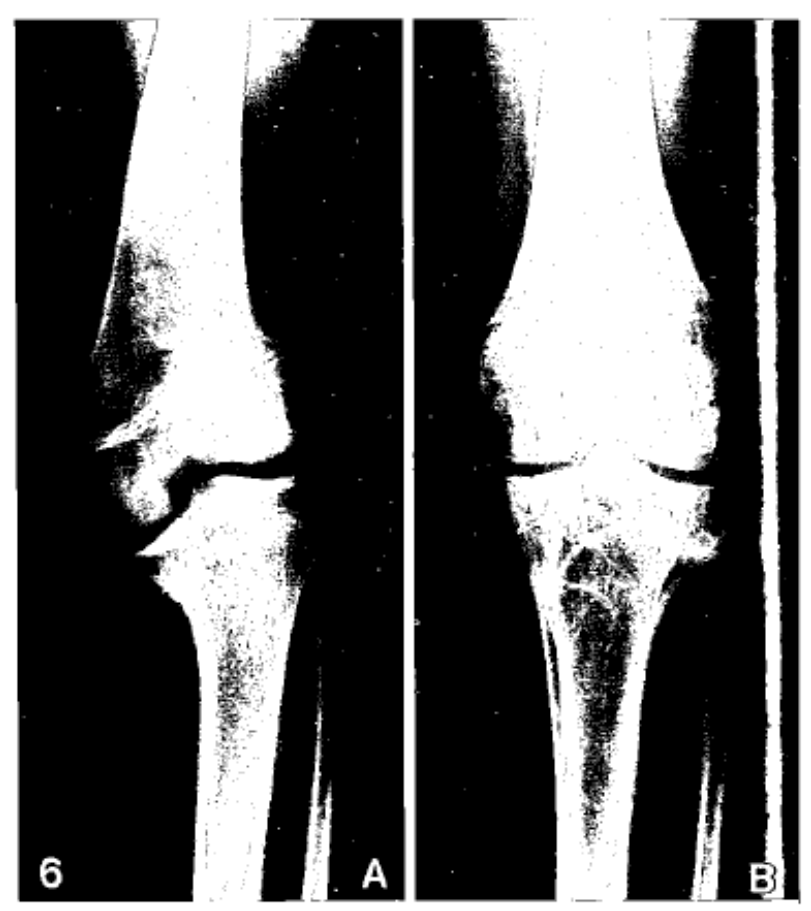

Figure 6 A, B. Case 2. A. P. radiograph. A Before operation and $\mathbf{B}$ one year after operation 


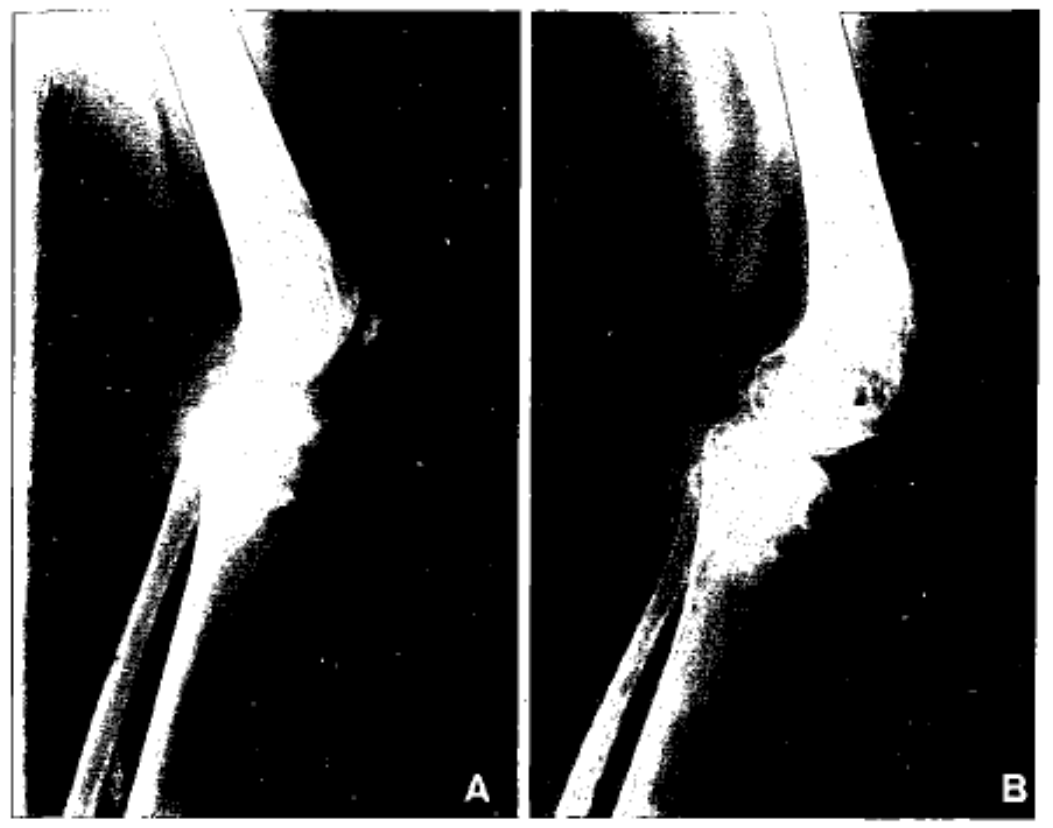

Figure 7 A, B. Case 2. Lateral radiograph. A Before operation and $\mathbf{B}$ one year after operation

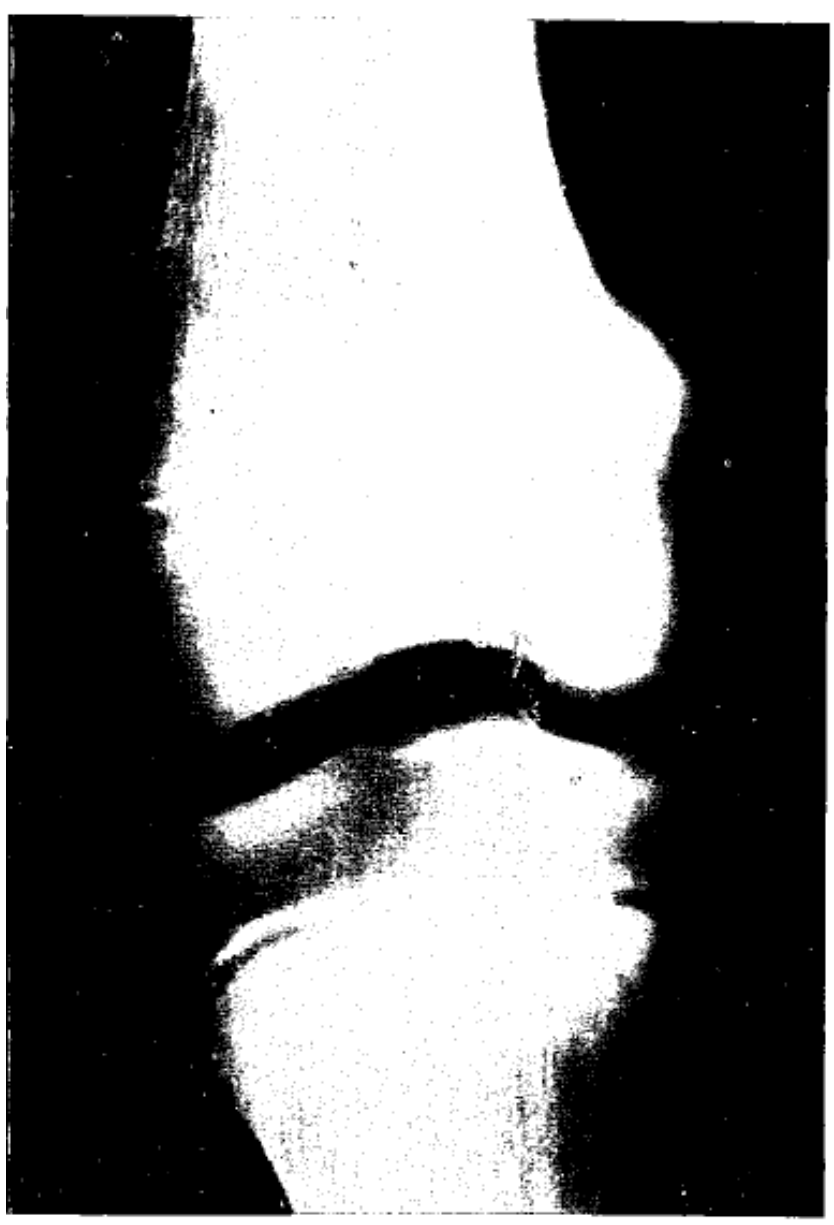

Figure 8. Case 3. Linear tomogram right knee 


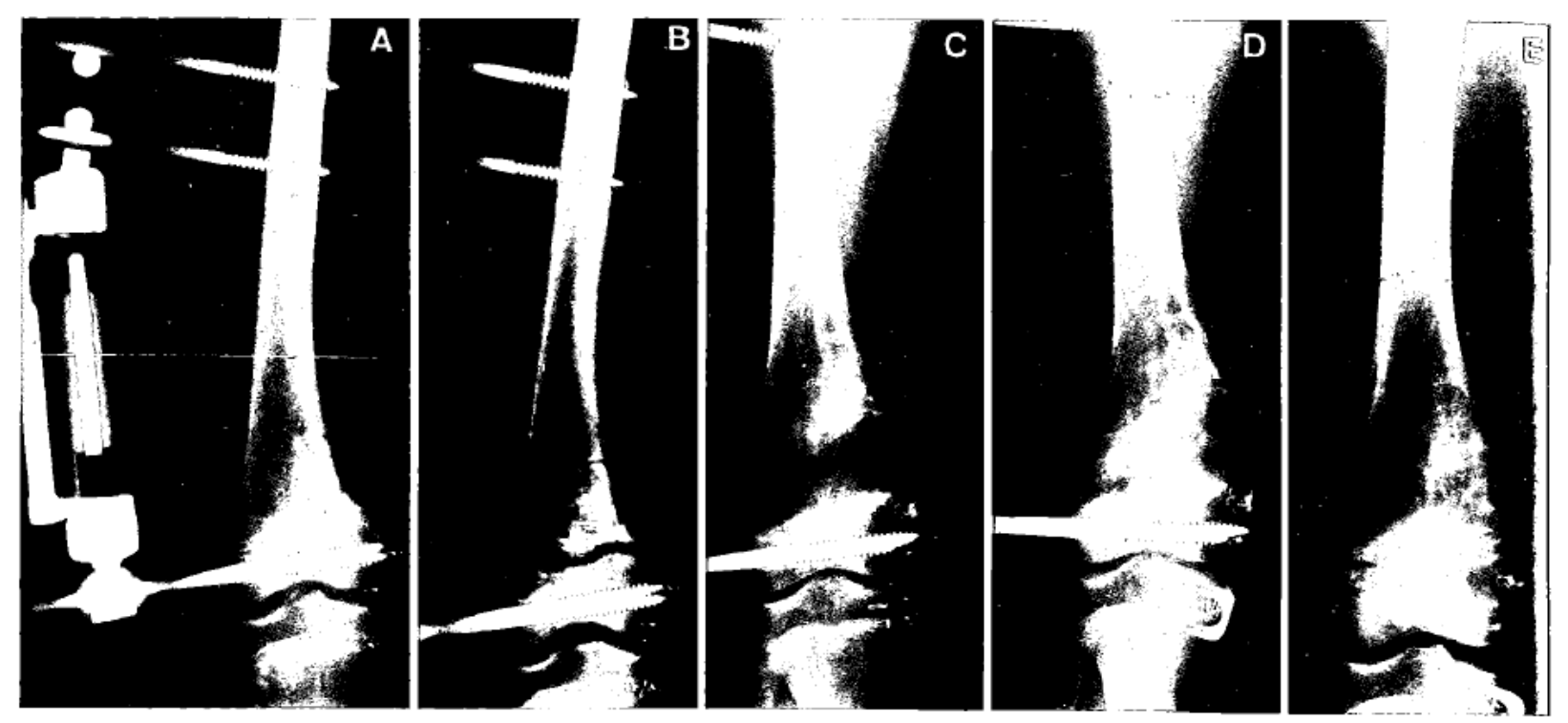

Figure 9 A-E. Case 3. A Immediately after operation; B 10 days after operation; C 5.5 $\mathrm{cm}$ of lengthening 2 months after operation; D angular deformity corrected 3 months after operation and $\mathbf{E} 9$ months after operation 